\title{
Corrigendum: Insights into the role of DNA methylation in diatoms by genome-wide profiling in Phaeodactylum tricornutum
}

Alaguraj Veluchamy, Xin Lin, Florian Maumus, Maximo Rivarola, Jaysheel Bhavsar, Todd Creasy, Kimberly O'Brien, Naomi A. Sengamalay, Luke J. Tallon, Andrew D. Smith, Edda Rayko, Ikhlak Ahmed, Stéphane Le Crom, Gregory K. Farrant, Jean-Yves Sgro, Sue A. Olson, Sandra Splinter Bondurant, Andrew E. Allen, Pablo D. Rabinowicz, Michael R. Sussman, Chris Bowler \& Leïla Tirichine

Nature Communications 4:2091 doi: 10.1038/ncomms3091 (2013); Published 2 Jul 2013; Updated 6 Jan 2014

In the original version of this Article, the middle initial of the author Andrew E. Allen was omitted from the author information. This has now been corrected in both the PDF and HTML versions of the Article. 